\title{
АНТРОПОЛОГИЯ ИНВАЛИДНОСТИ
}

УДК $39+2-486.7$

DOI: $10.33876 / 2311-0546 / 2021-53-1 / 33-35$

(С) Е.Э. Носенко-Штейн

\section{ЗАЧЕМ АНТРОПОЛОГАМ ИЗУЧАТЬ ИНВАЛИДНОСТЬ? (ВВЕДЕНИЕ В ТЕМУ)*}

\begin{abstract}
Инвалидность, являющаяся сложным сочиокультурным феноменом, имеющим биологические корни, до сих пор находится на обочине исследовательского интереса у отечественных этнологов и сочиильных антропологов. Между тем, это явление существует в определенном историко-культурном контексте, на его восприятие и осмысление, а также на отношение к людям с ограниченными возможностями здоровья оказывают влияние различныле культурные факторы: этнические и религиозные традиции, гендерныле стереотипь, особенности сочииальной психологии конкретных групп. В этой небольшой вводной статье автор стремится показать, что именно может привлечь этнологов и сочиальных антропологов $к$ данной проблематике. Среди тем, которые мало или вовсе не изучались отечественными учеными, можно назвать проблемы другой телесности в разных культурах, соотношение красоты, уродства и инвалидности в разные эпохи, существование особой культуры (или субкультур инвалидности), стили жизни людей с разными категориями инвалидности, этнические традиции помощчи или избегания людей с инвалидностью, репрезентация инвалидности в разных религиозных системах, формирование многочисленных стереотипов и клише, в том числе в современных обществах и многое другое.
\end{abstract}

Ключевые слова: инвалидность, люди с ограниченными возможностями здоровья, этнология, соџиокультурная антропология, Россия

Ссылка при цитировании: Носенко-Штейн Е.Э. Зачем антропологам изучать инвалидность? // Вестник антропологии, 2021. № 1 (53). С. 33-35.

Инвалидность представляет собой сложный биосоциальный и историко-культурный феномен. В основе этого явления, на первый взгляд, лежит физический или ментальный дефект, последствие заболевания или нарушение функций человеческого организма в результате заболевания, травмы или других причин. Однако не все столь просто. Отношение к инвалидности и людям с ограниченными возможностями здоровья (ОВ3) варьируют в разные эпохи и в различных культурах от резко негативного

Носенко-Штейн Елена Эдуардовна - д.и.н., ведущий научный сотрудник, Институт востоковедения РАН (107031 Москва, ул. Рождественка, 12). Эл.почта: nosenko1@gmail.com

* Исследование выполнено при финансовой поддержке Российского фонда фундаментальных исследований в рамках проекта № 20-09-00063 А «Инвалидность как социокультурный феномен на постсоветском пространстве: социально-антропологический и кросс-культурный анализ» 
до признания особых возможностей этих людей, которые должны быть использованы обществом для его гармоничного развития. На восприятие инвалидности и людей с OB3 оказывает воздействие множество факторов: наличие или недостаток ресурсов, особенности их распределения в данном обществе, религиозные и философские системы, наличие этнических, расовых и гендерных стереотипов и статусные различия. инвалидность конструируется в конкретных обществах в зависимости не только от указанных факторов, но и от политики властных элит, стремящихся контролировать распределение ресурсов и поведение различных социальных групп.

За последние три-четыре десятилетия сложилось несколько моделей изучения инвалидности/ Disability Studies, из которых основными обычно считают медицинскую и социальную. Если медицинская модель рассматривает инвалидность как следствие заболевания, нарушения функций организма, как психосоматическую травму и личную трагедию, а человека с ОВЗ как больного, которого следует лечить и о котором нужно заботиться, но от которого мало что зависит, то социальная модель сдвигает фокус с проблемы личности на проблемы общества. Согласно ей, инвалидность представляет собой конструкт, созданные в обществе ради контроля над наиболее дискриминируемыми группами, в том числе людьми с инвалидностью, и общество несет ответственность за такое положение. Обе модели подвергались и подвергаются критике, их недостатки частично восполняются в других моделях инвалидности (подробнее о некоторых из них см.: Ендальцева 2018; Носенко-Штейн 2018).

В нашей стране «пионером» в области изучения многих проблем инвалидности, а также «продвижения» социальной модели стала Е.Р. Ярская-Смирнова (Романов, Ярская-Смирнова 2006). Однако, в России до сих пор большинство работ по проблемам инвалидности посвящены различным аспектам социальной работы и социальной политики. Между тем, многие проблемы и неудачи социальной политики не в последнюю очередь обусловлены отсутствием базовых знаний об инвалидности как о «многослойном» комплексном феномене, о природе предрассудков и негативных стереотипов, распространенных в массовом сознании.

В России после ратификации Конвенции ООН о правах инвалидов (2012 г.) стали происходить некоторые изменения: попытки создания безбарьерной среды, внедрения инклюзивного образования. Однако многие благие начинания наталкиваются и я не устаю это повторять - на отсутствие элементарных знаний об инвалидности и людях с ОВЗ. окружающие почти ничего не знают о повседневных проблемах таких людей (как не знают об обратной стороне Луны (Курленкова, Носенко-Штейн 2018), а люди с ОВЗ (особенно инвалиды детства) нередко замкнуты в своем мире/субкультуре и живут в «параллельном мире».

Изучением многих проблем инвалидности и людей с ОВ3 могли бы заниматься этнологи и социальные антропологи, располагающие соответствующей методологией и знаниями особенностей различных культур. Одна из попыток такого рода с любезного разрешения редколлегии Журнала «Вестник антропологии» предпринята в настоящем номере журнала. Тематика раздела может показаться несколько «пестрой». Это отчасти объясняется тем, что многие темы в антропологии инвалидности даже не обозначены, а другие - изучены все еще слабо. Но вошедшие в этот раздел статьи объединены тем, что они исследуют феномен инвалидности в различных обществах, делая акцент на месте человека с ОВ3 в различных культурах. А последнее составляет предмет социокультурной антропологии. 


\section{Научная литература}

Ендальцева A.C. Disability Studies и поиски «чистой» модели: про швы, не-возможность и пространство: между Глобальным Югом и Глобальным Севером // Обратная сторона Луны, или что мы не знаем об инвалидности (теория, репрезентация, практики) / Отв. ред. Курленкова А.С, Носенко-Штейн Е.Э. М.: МБА, 2018. С. 43-74.

Курленкова А.С., Носенко-Штейн Е.Э. (Ред). Обратная сторона Луны, или что мы не знаем об инвалидности (теория, репрезентация, практики) М.: МБА, 2018.

Романов П., Ярская-Смирнова Е. Политика инвалидности: Социальное гражданство инвалидов в современной России. Саратов: Научная книга, 2006.

Носенко-Штейн Е.Э. Антропология инвалидности: проблемы и задачи // Этнографическое обозрение, 2018. № 1. С. 5-11.

Nosenko-Stein, Elena*

\section{Why do Anthropologists Study Disability? (Editor's Introduction)}

DOI: $10.33876 / 2311-0546 / 2021-53-1 / 33-35$

Disability exists as a complex social and cultural phenomenon having biological and medical roots. This phenomenon is still marginal in the research of Russian ethnologists and social anthropologists. However, disability exists in a particular historical and cultural context. Many factors - among them ethnic and religious traditions, gender stereotypes, and specifics of social psychology in different groups - impact on its perception, reflection and attitudes towards people with various impairments. The author attempts to demonstrate some issues that may be of importance for ethnological and anthropological research in Russia. For instance, these are problems of Extraordinary Bodies in various cultures, proportion of beauty, ugliness and impairments in different epochs, different disability cultures or subcultures, lifestyles of people with different disabilities, ethnic traditions of help or distancing disabled persons, representation of disability in various religious systems, constructing stereotypes dealing with disabilities in different societies including contemporary Russia, and some other issues.

Keywords: disability, people with disabilities, ethnology, social and cultural anthropology, Russia

For Citation: Nosenko-Stein, E. 2021. Why do Anthropologists Study Disability? Herald of Anthropology (Vestnik Antropologii) 1 (53): 33-35.

*Nosenko-Stein, Elena E. - Dr. (Hist), leading researcher, Institute for oriental Studies RAS (Moscow, Russia).E-mail: nosenko1@gmail.com

The research was supported by the Russian Foundation for Basic Research (RFFI, project No. 20-09-0063).

\section{References}

Kurlenkova A. and E. Nosenko-Stein (eds). 2018. Obratnaia storona Luny, ili chto my ne znaem ob invalidnosti (teoria, reprezentatsia, praktiki) [Back Side of the Moon, or What We do not Know about Disability (Theory, Representation, Practices)]. Moscow: MBA.

Nosenko-Stein, E. 2018. Antropologia invalidnosti: problymy i zadachi [Anthropology of Disability: Problemsand Perspectives]. Etnograficheskoye obozrenie 1: 5-11.

Romanov, P. and E. Iarskaia-Smirnova. 2006. Politika invalidnosti: sotsialnoye grazhdanstvo invalidov $v$ sovremennoy Rossii [Policy dealing with disability: social citizenship of disabled people in contemporary Russia]. Saratov: Nauchnaya kniga. 